Arq. Bras. Med. Vet. Zootec., v.68, n.1, p.82-86, 2016

\title{
Hemangiossarcoma ocular em um equino: relato de caso
}

\author{
[Equine ocular hemangiosarcoma: case report] \\ A.M. Carvalho ${ }^{1}$, T.C.P. Munhoz ${ }^{2}$, H.S. Toma ${ }^{1}$, M.A. Pires ${ }^{1}$, \\ G.D. Kommers ${ }^{3}$, G.J.N. Galiza ${ }^{1}$ \\ ${ }^{1}$ Faculdade de Medicina Veterinária -Universidade de Cuiabá -UNIC-Cuiabá, MT \\ ${ }^{2}$ Residente - Faculdade de Medicina Veterinária - UNIC- Cuiabá, MT. \\ ${ }^{3}$ Universidade Federal de Santa Maria -UFSM- Santa Maria, RS.
}

\begin{abstract}
RESUMO
O hemangiossarcoma ocular na espécie equina é um tumor maligno, raro e agressivo, de origem vascular endotelial. No presente trabalho, descreve-se um caso de hemangiossarcoma ocular em uma égua de 10 anos que apresentava secreção serossanguinolenta advinda de uma massa, acometendo a conjuntiva bulbar e a terceira pálpebra do olho direito. O diagnóstico foi realizado com base na avaliação histopatológica e na imuno-histoquímica. Foi realizada a enucleação, assim como a completa excisão cirúrgica do tecido acometido, não sendo observada, após seis meses da terapia, a recidiva ou a metástase da lesão.
\end{abstract}

Palavras-chave: neoplasia vascular, diagnóstico imuno-histoquímico, enucleação transpalpebral

\begin{abstract}
Equine ocular hemangiosarcoma is a rare and aggressive malignant tumor of vascular endothelial origin. We describe a case of ocular hemangiosarcoma in a 10-year-old mare with serosanguineous secretion arising from a mass involving the bulbar conjunctiva and third eyelid of the right eye. The diagnosis was based on histopathological evaluation and immunohistochemistry. Enucleation was performed as complete surgical excision of the affected tissue, with no recurrence or metastasis of the lesion being observed after six months of.
\end{abstract}

Keywords: vascular tumor, immunohistochemistry diagnostic, transpalpebral enucleation

\section{INTRODUÇÃO}

O hemangiossarcoma ocular na espécie equina é um tumor maligno agressivo raro, de origem vascular endotelial (Moore et al., 1986). É caracterizado pela rápida progressão, frequentemente sofre metástase e apresenta prognóstico desfavorável (Johns et al., 2005). A excisão cirúrgica, a enucleação e a radioterapia são exemplos de terapias empregadas, entretanto é comum a recidiva ou a ocorrência de metástase para outros tecidos, e, muitas vezes, a eutanásia é a única opção (Pinn et al., 2011).

O hemangiossarcoma ocular
tipicamente associado à $\quad \begin{array}{r}\text { descarga } \\ \text { dé }\end{array}$ serossanguinolenta do olho e da narina, originase da conjuntiva e frequentemente envolve a terceira pálpebra (Pinn et al., 2011). Entretanto, também pode acometer o globo ocular, o linfonodo local e o músculo facial (Sansom et al., 2006).

Além da ocorrência ocular na espécie equina, também há relato de hemangiossarcoma em diversos tecidos, como pele, seios paranasais, bolsa gutural, ovário, vagina, peritônio, baço, pericárdio, coração, pulmão, cérebro, bainha sinovial e sistema musculoesquelético (Barros, 1997; Johns et al., 2005; Sansom et al., 2006; Pinn et al., 2011).

Recebido em 17 de outubro de 2014

Aceito em 19 de junho de 2015

E-mail: armandodvm@gmail.com 
É incomum o acometimento do hemangiossarcoma ocular na espécie equina, e, portanto, escasso o número de casos relatados (Pinn et al., 2011). Objetiva-se, neste trabalho, relatar o caso clínico, o método diagnóstico e o tratamento empregados em um caso de hemangiossarcoma ocular equino.

\section{DESCRIÇÃO DO CASO}

Foi atendida, no Hospital Veterinário da Universidade de Cuiabá (HV-UNIC), uma égua de raça indefinida, com 10 anos de idade e histórico de crescimento repentino de massa no globo ocular direito, com evolução de 14 dias. Ao exame físico, evidenciou-se secreção serossanguinolenta advinda de massa envolvendo a conjuntiva bulbar e a terceira pálpebra, que encobria praticamente todo o olho do animal, associada ao inchaço acentuado da pálpebra e quemose da conjuntiva palpebral (Fig. 1).

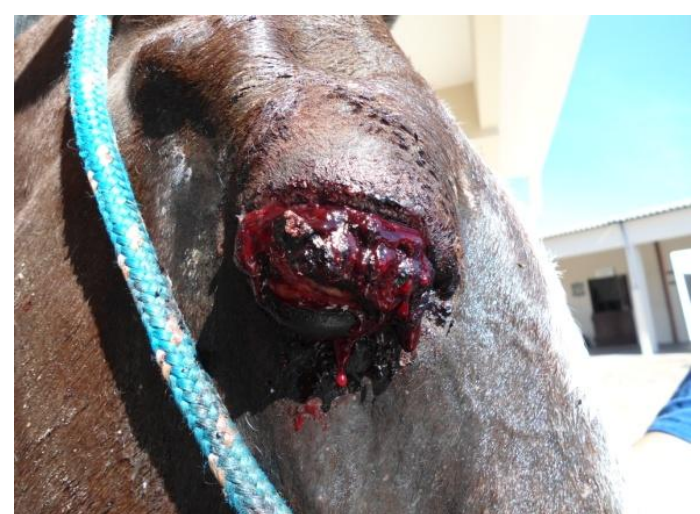

Figura 1. Secreção serossanguinolenta advinda da massa envolvendo a conjuntiva bulbar e a terceira pálpebra do globo ocular direito.

Não foi possível fazer avaliação oftalmológica completa, devido à presença da massa, já que, na inspeção, era possível a visualização apenas da porção dorsal da córnea, abaixo da pálpebra superior. $\mathrm{O}$ animal apresentava dor à palpação. Devido ao contínuo aumento de volume e à ausência de resposta ao tratamento com iodopovidona tópico $0,1 \%$ duas vezes ao dia, optou-se pela intervenção cirúrgica para excisão da massa tumoral.

Para isso, o animal foi submetido à anestesia geral inalatória e posicionado em decúbito lateral esquerdo. Com auxílio de um bisturi elétrico, realizou-se a excisão cirúrgica do tecido conjuntivo ocular. Durante o ato cirúrgico, notou-se completo comprometimento do globo ocular, sendo realizada a técnica de enucleação transpalpebral conforme prévia descrição (Gilger, 2009). Foram coletados sete fragmentos da massa tumoral, que foram fixados em solução tamponada de formol a $10 \%$. No pós-operatório, a égua foi tratada com administração intramuscular de penicilina benzatina (22000UI/kg a cada 48 horas), em um total de três aplicações, e administração intramuscular de flunixin meglumine $(1,1 \mathrm{mg} / \mathrm{kg}$ a cada 24 horas), em um total de sete aplicações, além de curativos diários a cada 12 horas, com solução de iodopovidona tópica a $0,1 \%$, até a retirada da sutura, aos 12 dias de pós-operatório.

$\mathrm{Na}$ avaliação histopatológica, observou-se proliferação de células fusiformes dispostas em forma de canais vasculares, preenchidos por eritrócitos, apoiadas em um estroma de colágeno com áreas multifocais de moderado infiltrado inflamatório neutrofílico (Fig. 2). Em alguns fragmentos da massa, observava-se proliferação de tecido de granulação. Pela técnica de imunohistoquímica utilizando-se o anticorpo antifator de von Willebrand (previamente denominado antígeno associado ao fator VIII), observou-se imunomarcação de parte das células neoplásicas endoteliais presentes na massa tumoral (Fig. 2).

Após o diagnóstico, o proprietário foi esclarecido quanto ao prognóstico reservado deste caso e à possibilidade de recidiva e metástases para outros órgãos. Após 21 dias, houve a completa cicatrização da ferida cirúrgica e o animal recebeu alta médica. Foi realizada a reavaliação clínica do animal após seis meses da cirurgia, e não foram observadas recidiva no local ou metástases para linfonodos regionais. 


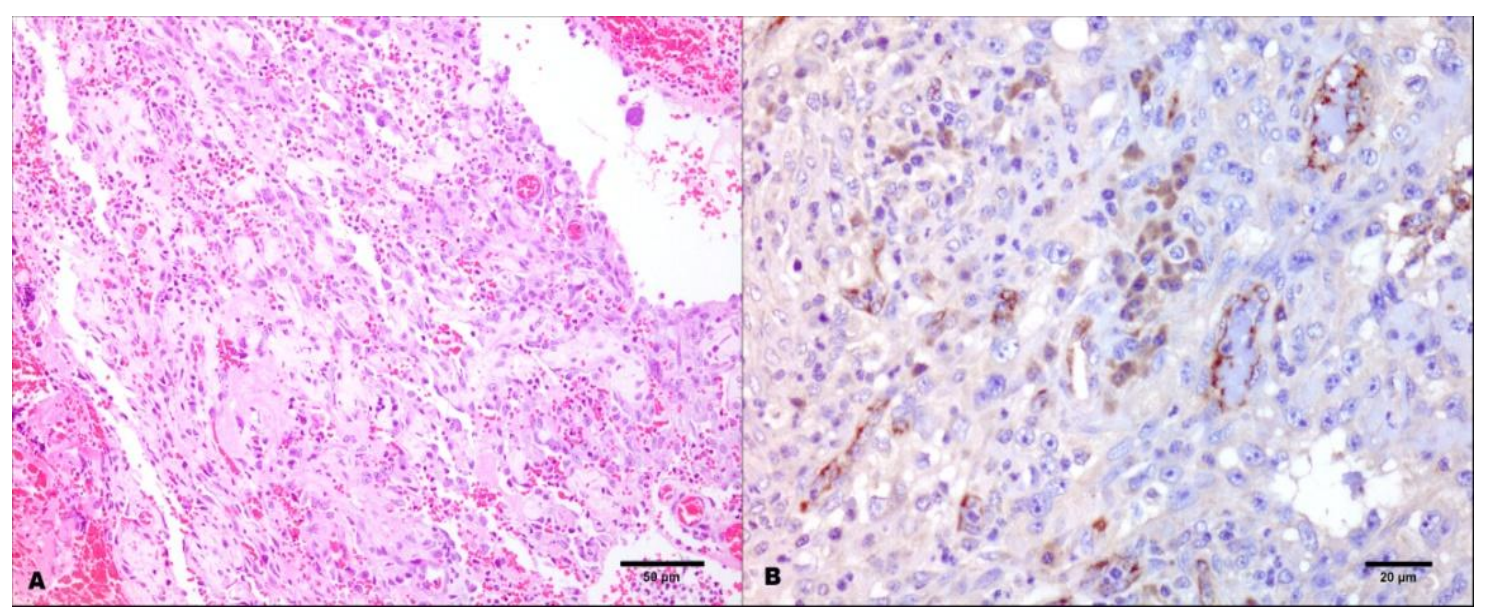

Figura 2. Hemangiossarcoma ocular, equino. A) Massa tumoral composta por células fusiformes dispostas em forma de canais vasculares, preenchidos por eritrócitos, apoiadas em estroma de colágeno. HE. Barra 50 $\mu \mathrm{m}$. B) Imunomarcação citoplasmática positiva de parte das células neoplásicas endoteliais. Imuno-histoquímica utilizando o anticorpo antifator de von Willebrand (previamente denominado antígeno associado ao fator VIII) e o método estreptavidina-biotina-peroxidase. Barra $20 \mu \mathrm{m}$.

\section{DISCUSSÃO}

O desenvolvimento de hemangiossarcoma aos 10 anos de idade da égua sem raça definida do presente estudo é compatível com relatos previamente descritos, pois não existe predileção do hemangiossarcoma ocular em equino por raças ou gênero, entretanto é mais comum o aparecimento desse tipo de tumor em animais velhos e de meia-idade, com idade variando entre seis e 26 anos (Sansom et al., 2006; Gearhart et al., 2007; Arenas-Gamboa e Mansell, 2011; Pinn et al., 201; Gupta et al., 2012).

Estudos indicam que a exposição prolongada à luz ultravioleta pode ser um possível indutor de neoplasmas oculares como o hemangiossarcoma e o carcinoma de células escamosas em equinos (Moore et al., 1986; Gearhart et al., 2007; Pinn et al., 2011). Neste relato, o animal era criado em piquete exposto à radiação solar, sugerindo que a ação dos raios ultravioletas possa ter favorecido o desenvolvimento do tumor vascular em áreas do corpo pouco protegidas, como a conjuntiva e a terceira pálpebra.

Os possíveis diagnósticos diferenciais para hemangiossarcoma ocular incluem outros tipos de neoplasias oculares, como carcinoma de células escamosas, e sarcoide, além de outras enfermidades, como habronemose cutânea e tecido de granulação exuberante (Sansom et al., 2006). O diagnóstico mediante biópsia cirúrgica e avaliação histopatológica é essencial para a escolha do melhor protocolo terapêutico (Pinn et al., 2011).

Métodos de diagnóstico por imagem, como a ultrassonografia, a tomografia computadorizada e a ressonância magnética, também podem ser utilizados para avaliação ocular. A avaliação ultrassonográfica é possível de ser executada com a sedação do animal, enquanto a realização dos outros exames é mais restrita por requerer a anestesia geral para o procedimento, além da indisponibilidade desses equipamentos na maioria dos hospitais veterinários (Pierce e Townsend, 2012). Há descrição de ultrassonografia em casos de hemangiossarcoma em equino com massas de tecidos moles hipoecoicos a ecoicos contendo fluido anecoico em seu interior (Johns et al., 2005).

No caso relatado, o diagnóstico foi realizado após completa ressecção cirúrgica da massa tumoral e avaliação histológica de várias secções da massa, sendo esse dado compatível com o relatado por Smith (2003), o que evidencia a necessidade de múltiplas amostras de biópsia para a confirmação do diagnóstico, já que a massa tumoral normalmente não é homogênea e muitas áreas podem assemelhar-se a hematomas.

O termo "angiossarcoma" é utilizado para a denominação de tumores de células endoteliais vasculares e de células endoteliais linfáticas, de 
hemangiossarcoma e de linfangiossarcoma (Arenas-Gamboa e Mansell, 2011). A diferenciação entre os dois tipos de tumores normalmente é baseada nas avaliações histopatológica e imuno-histoquímica (Pinn et al., 2011) e pode ser confirmada por meio da expressão do Prospera-related homebox gene 1 (PROX-1), que é um marcador exclusivo do endotélio linfático (Junginger et al., 2010). No presente relato, o diagnóstico foi realizado com base no exame histopatológico e na imunomarcação positiva para fator de von Willebrand.

Segundo Moore e colaboradores (1986), a diferenciação também pode ser baseada na intensidade de marcação do fator VIII, sendo esta presente nas células endoteliais dos vasos sanguíneos e presente em menor intensidade nas células endoteliais ao redor dos vasos linfáticos. Entretanto, segundo Johns e colaboradores (2005), a expressão do fator VIII não pode ser utilizada para a diferenciação de endotélios normal e neoplásico, sendo assim de uso limitado quando se trata de tumores pouco diferenciados.

Embora o prognóstico seja desfavorável e o tratamento seja considerado mais paliativo que curativo, a enucleação mostrou-se eficaz, não sendo observada recidiva ou metástase para outros tecidos. O tratamento adotado é condizente com o relatado em estudos anteriores, que indicam a excisão radical da massa tumoral, seja por meio da enucleação ou da exenteração, seguida ou não de radioterapia (Sansom et al., 2006; Pinn et al., 2011). A ausência de recidivas ou metástase desse caso clínico pode ser associada à rapidez no diagnóstico e na intervenção cirúrgica, evitando o comprometimento de tecidos adjacentes, e, em parte, ao melhor prognóstico dos casos de hemangiossarcoma quando há uma única lesão inicial (Southwood et al., 2000). Segundo Johns e colaboradores (2005), se o diagnóstico e o tratamento forem realizados antes da infiltração ou da metástase tumoral, a ressecção pode ser curativa.

\section{CONCLUSÕES}

Informações referentes ao diagnóstico, tratamento e prognóstico relacionados à hemangiossarcoma na espécie equina são escassas. Da mesma forma, não é comum encontrar o hemangiossarcoma como diagnóstico diferencial de neoplasias oculares. A avaliação histopatológica, aliada à imuno-histoquímica, foi essencial para a realização do diagnóstico. Embora ainda possa haver recidiva ou metástase tumoral do caso descrito, o rápido diagnóstico, associado à excisão cirúrgica antes da progressão da massa tumoral, foi fundamental para $o$ aumento da sobrevida deste animal. Este relato consta como o primeiro caso de hemangiossarcoma ocular em equino descrito no Brasil.

\section{REFERÊNCIAS}

ARENAS-GAMBOA, A.M.; MANSELL, J. Epithelioid haemangiosarcoma in the ocular tissue of horses. J. Comp. Pathol., v.144, p.328333, 2011.

BARROS, C.S.L. Vertebral hemangiosarcoma as a cause of spinal cord compression in a horse. Cienc. Rural, v. 27, p.503-504, 1997.

GEARHART, P.M.; STEFICEK, B.A.; PETERESEN-JONES, S.M. Hemangiosarcoma and squamous cell carcinoma in the third eyelid of a horse. Vet. Ophthalmol., v.10, p.121-126, 2007.

GILGER, B.C. Enucleation. In: ROBINSON, N.E.; SPRAYBERRY, K.A. Current therapy in equine medicine. 6.ed. St. Louis: Elsevier, 2009. p.655-659.

GUPTA, A.; BHASKARAN, M.; STOREY, E. et al. What is your diagnosis? Fine-needle aspirate of a third eyelid mass in a Paint horse. Vet. Clin. Pathol., v.41, p.299-300, 2012.

JOHNS, I.; STEPHEN, J.O; DEL PIERO, F. et al.Hemangiosarcoma in 11 young horses. J. Vet. Intern. Med., v.19, p.564-570, 2005.

JUNGINGER, J.; ROTTING, A.; STASZYK, C. et al. Identification of equine cutaneous lymphangioma by application of lymphatic endothelial cell marker. J. Comp. Pathol., v.143, p.57-60, 2010 .

MOORE, P.F.; HACKER, D.V.; BUYUKMIHEI, N.C. Ocular angiosarcoma in the horse: morphlogical and immunohistochemical studies. Vet. Pathol., v.23, p.240-244, 1986. 
PIERCE, K.E.; TOWNSEND, W.M. Surgery of the globe and orbit. In: AUER, J.A.; STICK, J.A. (Eds.). Equine surgery. 4 ed. St. Louis: Elsevier, 2012. p.728-743.

PINN, T.L.; CUSHING, T.; VALENTINO, L.M. et al. Corneal invasion by hemangiosarcoma in a horse. Vet. Ophthalmol., v.14, p.200-204, 2011.

SANSOM, J.; DONALDSON, D.; SMITH, K. et al.Haemangiosarcoma involving the third eyelip in the horse: a case series. Equine Vet. J., v.38, p.277-282, 2006.
SMITH, A.N. Hemangiosarcoma in dogs and cats. Vet. Clin. N. Am-Small., v.33, p.533-552, 2003.

SOUTHWOOD, L.L.; SCHOTT, H.C.; HENRY, C.J. et al. Disseminated hemangiosarcoma in the horse: 35 cases. J. Vet. Inter. Med., v.14, p.105109, 2000. 